\title{
Pulmonary hypertension in pulmonary agenesis-a report of five pediatric cases and review of previous cases.
}

\author{
Zhiyuan Wu ${ }^{1 \#}$, Yingkang Jin ${ }^{2 \#}$,Yunlong Zuo ${ }^{1}$, Wenmin Yang1, Jian Wang², Yiyu Yang ${ }^{\text {* }}$ \\ ${ }^{1}$ Guangzhou Women and Children's Medical Center, Guangzhou, Guangdong, People's Republic of China \\ ${ }^{2}$ Department of Laboratory Medicine, Guangzhou Institute of Respiratory Diseases, State Key Laboratory of \\ Respiratory Diseases, the First Affiliated Hospital, Guangzhou Medical University, China \\ \#These authors contributed equally to this study
}

\begin{abstract}
Pulmonary Agenesis (PA) is a rare congenital malformation of lung development, and patients with comorbid Pulmonary Hypertension (PH) have substantially increased morbidity and mortality risks. We describe five pediatric cases born with unilateral PA who developed PH. By integrating our findings with those of 7 previously published case reports, we aim to provide a more complete description of disease features, prognosis, and the most effective treatment strategies. We found that male PA patients and those with right-side agenesis were more likely to develop PH. Moreover, half of these comorbid patients had congenital heart disease with left-to-right shunt. Early diagnosis and treatment, including surgical and medical interventions, are critical for preservation of cardiopulmonary function. All PA cases should receive regular cardiopulmonary function tests starting at an early age.
\end{abstract}

Keywords: Pulmonary agenesis, Congenital malformations, Pulmonary hypertension, Co-existing anomalies.

Accepted on April 27, 2018

\section{Introduction}

Pulmonary Agenesis (PA) is a rare congenital defect of lung development first described by De Pozze at autopsy of an adult female. According to the classification of Schneider and Schwabble [1], pulmonary agenesis patients are divided into three groups: type 1 with agenesis (complete absence of lung, bronchus, and vascular supply), type 2 with aplasia (absent lung tissue and pulmonary artery, but a rudimentary bronchus projecting from the trachea), and type 3 with hypoplasia (hypoplastic lung and a rudimentary bronchial tree).

Bilateral PA is incompatible with life, while unilateral cases may survive in the absence of other fatal malformations. Pulmonary agenesis is associated with numerous additional congenital abnormalities of the cardiovascular, musculoskeletal, genitourinary, and gastrointestinal systems that may negatively impact prognosis. Pediatric PA patients also present with varying degrees of Pulmonary Hypertension (PH) [2-8], but effects of $\mathrm{PH}$ on disease course and prognosis are uncertain, and there are no widely accepted treatment standards. Therefore, we describe five pediatric cases born with unilateral PA who developed $\mathrm{PH}$, and review already published cases for a more complete description of disease features, clinical course, and treatment options.

\section{Patients and Methods}

Patients meeting the Schneider and Schwabble definition of PA [1] were enrolled from two institutes in Guangzhou, China: Guangzhou Children's Hospital and Guangzhou Institute of Respiratory Disease and State Key Laboratory of Respiratory Disease. The following information was collected: maternal and parental history, sex, co-existent malformations, treatment history, imaging features, and outcomes. Mutations in BMPR2, ALK1, and SMAD9 were also examined. Follow-up duration ranged from one month to five years depending on outcome.

All five patients fulfilled diagnostic criteria $\mathrm{A}$ and (or) $\mathrm{B}$ [9,10]: (A) mean pulmonary artery pressure (mPAP) $\geq 25$ $\mathrm{mmHg}$ and Pulmonary Vascular Resistance Index (PVRI) $>3$ Wood units as measured by right heart catheterization; (2) right ventricular hypertrophy, dilated Main Pulmonary Artery (MPA), and tricuspid regurgitation with maximum velocity $>2.5 \mathrm{~m} / \mathrm{s}$ as measured by echocardiography. A systematic literature search of PubMed using the terms "pulmonary/lung agenesis and pulmonary hypertension", "pulmonary/lung agenesis and right ventricular failure", and "pulmonary/lung agenesis and dilated pulmonary artery" was also performed to find similar pediatric cases (0-18 y old). Information from these published cases and our five new cases was compiled to evaluate demographics, co-anomalies, interventions, and outcomes. 


\section{Results}

We identified five pediatric PA cases with $\mathrm{PH}$ by institutional record review. The clinical presentations were all atypical, with most presenting with varying degrees of tachypnea, cyanosis, and thoracic asymmetry. No mutations in BMPR2, ALK1, or SMAD9 were found. The imaging features of these five patients are shown in Figures 1-4.
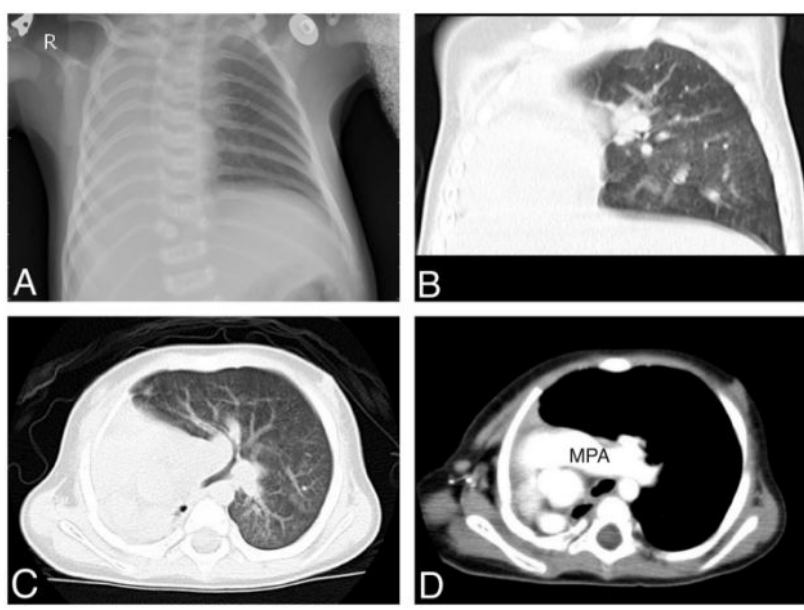

Figure 1. (A) X-ray (posterior-anterior view) from case 3 revealing homogenous right-side opacity. (B-D): CT scans from case 4 showing right lung, right bronchus, and pulmonary vasculature absence with hyper-inflated left lung, enlarged Main Pulmonary Artery (MPA), cardiac displacement to the right, and thoracic asymmetry.

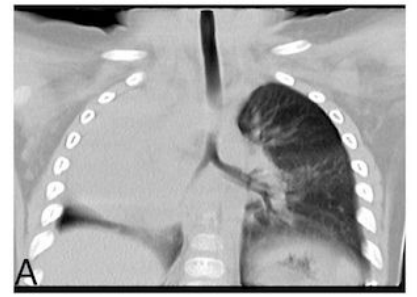

C

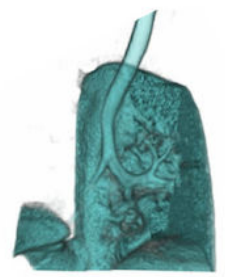

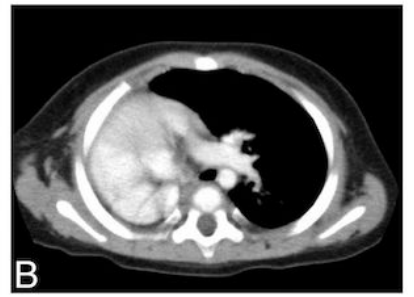

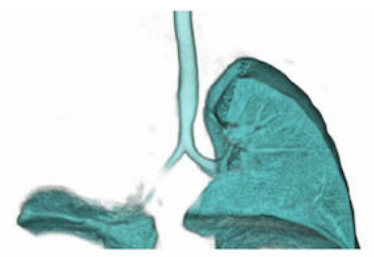

Figure 2. (A and B) CT scans from case 2 showing absence of right pulmonary artery and right upper and middle lobes. (C) Threedimensional reconstructed images showing right bronchial stenosis with the lower right lobe.

Other clinical features, co-existing anomalies, treatments, and follow-up results for the institutional population (Cases 1-5) and the seven previous cases retrieved from PubMed are summarized in Table 1. Except for case 3 (the female twin of a healthy male conceived by in vitro fertilization, born by cesarean delivery at $32 \mathrm{w}$ ' gestational age and weighing 1,480 $\mathrm{g}$ ), all patients were full-term with normal maternal and perinatal histories.
Male PA patients (M: $\mathrm{F}=2: 1)$ and those with right-sided agenesis (right: left=3:1) were more likely to develop $\mathrm{PH}$. Moreover, 50\% of PA patients with $\mathrm{PH}$ had congenital heart disease with left-to-right shunt, mainly Patent Ductus Arteriosus (PDA) and/or Arterial Septal Defect (VSD), one in sixth had diaphragmatic hernia, and one in twelve presented with bronchopulmonary fistula and bronchopulmonary foregut malformation. Five cases died before two years of age from repeated respiratory infection or unresolved $\mathrm{PH}$. The seven surviving patients are doing well with normal growth and development. Congenital anomalies (congenital heart disease or diaphragmatic hernia) have been repaired and $\mathrm{PH}$ controlled by drugs.
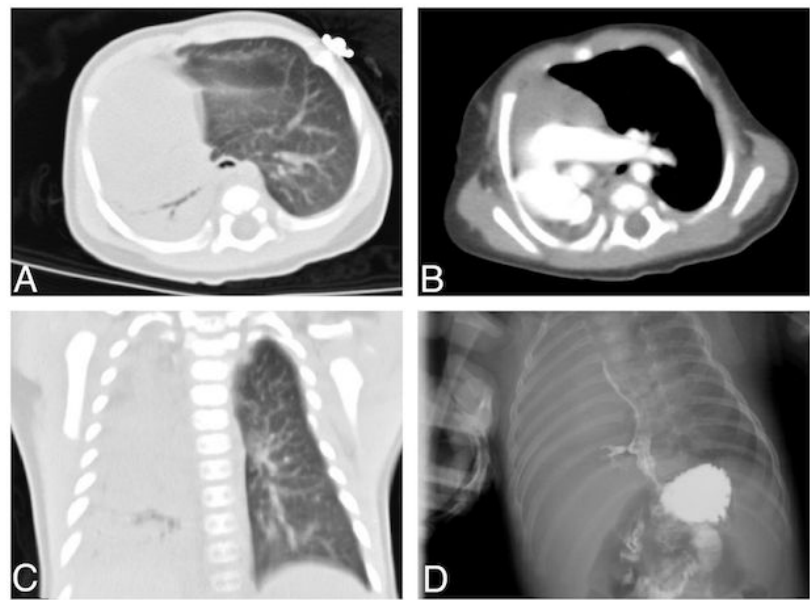

Figure 3. (A-C) CT scans from case 1 showing cardiac displacement to the right and left lung hyperinflation, absence of right bronchus and right pulmonary artery, and a small volume of residual lung tissue in the right hemi-thorax. (D) Upper gastrointestinal contrast image from Case 1 showing bronchopulmonary foregut malformation.

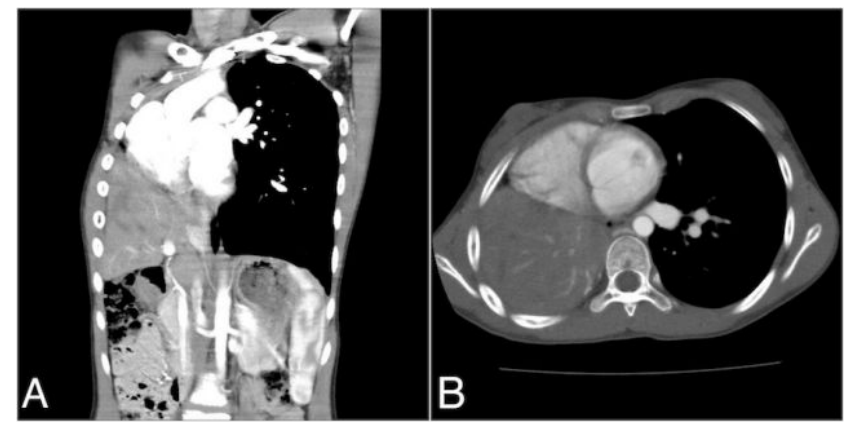

Figure 4. (AB) CT scans from case 5 showing diaphragmatic hernia in right thorax and cardiac displacement to the right.

\section{Discussion}

Unilateral PA is an extremely rare congenital anomaly, with an estimated prevalence between $1 / 10,000$ and $1 / 15,000$ live births and a slight preponderance in females (1.3:1) [11]. Genetic anomalies, viral infections, and vitamin A deficiency have all been proposed as causative factors, but etiology is usually uncertain [12]. 
The exactly incidence of comorbid $\mathrm{PH}$ is also unclear. The pathophysiology of $\mathrm{PH}$ in $\mathrm{PA}$ may involve early aberrant pulmonary vascular remodeling. Changes in pulmonary vasculature begin immediately at first breath. In the healthy developing lung, alveolar dissension, mechanical force, and exposure to oxygen cause a drop in Pulmonary Vascular Resistance (PVR) and an increase in pulmonary blood flow. In PA, however, the contralateral lung may carry markedly increased blood flow, leading to higher shear stress on the endothelium, with subsequent release of vasoconstrictors that increase PVR. Half of all patients with PH presented with VSD and/or PDA, and PH developed more frequently in unilateral right than left PA. Right ventricular overload due to left-right shunt and greater mediastinal shift due to right-side PA renders pulmonary arterial beds more susceptible to vascular remodeling. We also found that all deaths occurred before 2 years of age due to heart failure. The alveolar stage of human lung development spans the late infant period to age 7-8 y [13]. Remodeling of pulmonary arterioles due to persistent $\mathrm{PH}$ may destroy pulmonary vascular beds and adversely affect lung development. Two infants surviving beyond two years (Table 1) had received early intra-cardiac shunts and diaphragmatic hernia repair, suggesting that early protection and preservation of cardiopulmonary function may prevent vasculature remodeling and destruction.

Table 1. Characteristics of pulmonary hypertension in pulmonary agenesis and associated co-existing anomalies, treatments, and outcomes.

\begin{tabular}{|c|c|c|c|c|c|c|c|}
\hline Case & Age/sex & Investigation & $\begin{array}{l}\text { Side } \\
\text { affected }\end{array}$ & Co-malformation & Recurrent RTI & $\begin{array}{l}\text { Surgery and } \mathrm{PH}- \\
\text { targeted therapy }\end{array}$ & Outcome and follow-up \\
\hline Case 1 & $23 \mathrm{~d} / \mathrm{M}$ & CATH echo & $\mathrm{R}$ & BPMF PDA & yes & No & Died at 7 months \\
\hline Case 2 & $8 \mathrm{~m} / \mathrm{M}$ & CATH echo & $\mathrm{R}$ & $\begin{array}{l}\text { Tracheal stenosis } \\
\text { with right low lobe }\end{array}$ & yes & No & Died at 14 months \\
\hline Case 3 & $9 \mathrm{~m} / \mathrm{M}$ & CATH echo & $\mathrm{R}$ & PDA & yes & $\begin{array}{l}\text { Oral bosentan one } \\
\text { month }\end{array}$ & Died at 15 months \\
\hline Case 4 & $11 \mathrm{~m} / \mathrm{F}$ & CATH echo & $\mathrm{R}$ & None & no & $\begin{array}{l}\text { Oral bosentan two } \\
\text { years }\end{array}$ & $\begin{array}{l}\text { At } 6 \text { year follow-up with } \\
\text { normal status }\end{array}$ \\
\hline Case 5 & $11 \mathrm{y} / \mathrm{F}$ & CATH echo & $\mathrm{R}$ & $\mathrm{CDH}$ & no & $\begin{array}{l}\text { Oral bosentan } 6 \\
\text { months }\end{array}$ & $\begin{array}{l}\text { At } 2 \text { year follow-up with } \\
\text { normal status }\end{array}$ \\
\hline De-Leno [6] & $1 \mathrm{~d} / \mathrm{M}$ & Echo & $\mathrm{R}$ & TEF & no & No & Died at 1 month \\
\hline \multirow[t]{2}{*}{ Dobremez [4] } & \multirow[t]{2}{*}{$1 \mathrm{~m} / \mathrm{M}$} & \multirow[t]{2}{*}{$\begin{array}{l}\text { dilated pulmonary artery in } \\
\text { CT }\end{array}$} & \multirow[t]{2}{*}{$\mathrm{R}$} & \multirow[t]{2}{*}{ Tracheal stenosis } & \multirow[t]{2}{*}{ no } & \multirow[t]{2}{*}{$\begin{array}{l}\text { Tissue expander } \\
\text { placement }\end{array}$} & Alive at 3 year follow-up \\
\hline & & & & & & & $\begin{array}{l}\text { Compatible with normal } \\
\text { life }\end{array}$ \\
\hline Nakayama [7] & $12 \mathrm{~d} / \mathrm{M}$ & Echo & $\mathrm{R}$ & VSD PDA & no & $\begin{array}{l}\text { VSD repaired, } \\
\text { PDA division }\end{array}$ & $\begin{array}{l}\text { Alive at } 1 \text { year follow-up } \\
\text { with normal status }\end{array}$ \\
\hline \multirow[t]{2}{*}{ Nazir [3] } & \multirow[t]{2}{*}{$2 \mathrm{~m} / \mathrm{M}$} & \multirow{2}{*}{$\begin{array}{llr}\text { dilated } & \text { right } & \text { pulmonary } \\
\text { artery } & \text { detected } & \text { during } \\
\text { surgery } & & \\
\end{array}$} & \multirow[t]{2}{*}{ L } & PDA ASD & \multirow[t]{2}{*}{ no } & \multirow[t]{2}{*}{ PDA division } & Survived \\
\hline & & & & Left kidney absent & & & Duration not mentioned \\
\hline \multirow[t]{2}{*}{ Palma [2] } & \multirow[t]{2}{*}{$2 \mathrm{y} / \mathrm{M}$} & \multirow[t]{2}{*}{ Echo } & \multirow[t]{2}{*}{ L } & \multirow[t]{2}{*}{ CDH VSD ASD } & \multirow[t]{2}{*}{ no } & \multirow[t]{2}{*}{$\begin{array}{l}\mathrm{CDH} \text { and } \mathrm{VSD} \\
\text { repaired }\end{array}$} & Survived \\
\hline & & & & & & & Duration not mentioned \\
\hline Guo [8] & $5 \mathrm{y} / \mathrm{F}$ & CATH Echo & $\mathrm{L}$ & VSD & no & VSD repaired & $\begin{array}{l}\text { Alive at } 2 \text { year follow-up } \\
\text { with normal status }\end{array}$ \\
\hline Muensterer [5] & $4 \mathrm{~d} / \mathrm{M}$ & Echo & $\mathrm{R}$ & Tracheal stenosis & no & $\begin{array}{l}\text { Tissue expander } \\
\text { placement }\end{array}$ & Died at 5 months \\
\hline
\end{tabular}

Abbreviations: ASD: Atrial Septal Defect; BPMF: Bronchopulmonary Foregut Malformation; CATH: Catheterization; CDH: Diaphragmatic Hernia; d: day; Echo: Echocardiography; F: Female; L: Left; M: Male; m: month; PDA: Patent Ductus Arteriosus; R: Right; RTI: Respiratory Tract Infection; TEF: Tracheosophageal Fistula; VSD: Ventricle Septal Defect; y: year.

For type $2 \mathrm{PA}$, it is necessary to determine the origin of the vasculature supplying ipsilateral residual lung tissue. If the supply vessel comes from the systemic circulation, residual lung tissue will have minimal function due to low oxygen tension in alveoli and show repeated infection due to impaired mucociliary clearance and diminished delivery of appropriate inflammatory cells. Hypertrophic collateral vessels from relatively larger systemic vessels also lead to hemoptysis. When recurrent hemoptysis or severe pulmonary infections are present, lobectomy or pneumonectomy should be considered. In this report, case 3 lacking a right pulmonary artery but retaining a right lower lobe died of recurrent lung infections. Thus, we had no opportunity to further investigate the most effective interventions for such cases.

Right heart catheterization is the gold standard for definitive $\mathrm{PH}$ diagnosis (mPAP $\geq 25 \mathrm{mmHg}$, PVRI $>3$ Wood units). Echocardiography, cardiac CT scan, and cardiac magnetic 
resonance imaging are also fundamental diagnostic tools to screen for $\mathrm{PH}$ and assess cardiac anatomy. Right lung agenesis combined with tracheoesophageal fistula is an exceedingly rare but highly lethal combination [14] for which bronchoscopy or upper gastro-intestinal contrast imaging is recommended for diagnosis. Pulmonary angiogram or CTA is also important to define the intrapulmonary supply vessel in type 2 or type 3 PA.

Progressive $\mathrm{PH}$ is often responsible for clinical deterioration of PA patients and thus has a major influence on long-term prognosis. Early surgery to repair intra-cardiac shunts could reduce blood volume and diminish the chance of irreversible pulmonary vasculature remodeling. Other measures for timely repair of co-malformations, such as trachea-esophageal fistula and bronchial stenosis, could reduce adverse effects on the cardiopulmonary system. Tissue expanders have been implanted to prevent distortion and rotation of the main bronchus and great vessels caused by right-side agenesis. However, two published pediatric PA cases with PH adopting tissue expander placement yielded completely different outcomes, with one survival and one fatality $[3,4]$. Further case studies are necessary to confirm the efficacy of tissue expander implantation. For patents exhibiting deterioration despite surgery or other treatments, heart-lung transplantation should be considered.

Medications for PH may delay the structural remodeling process. Vaccines to reduce the frequency of respiratory tract infections and oxygen therapy to maintain suitable ventilation/ perfusion ratio are both useful preventative measures. The endothelia receptor antagonist bosentan was used successfully to improve status in two of our cases (Cases 3 and 5, although case 3 ultimately died). Bosentan is considered safe and effective for Pulmonary Arterial Hypertension associated with Congenital Heart Disease (CHD-PAH), whereas there is insufficient evidence for the efficacy of other PH-targeted drugs (such as the PDE5 inhibitor or prostacylin) [15]. Further studies on animal models and human studies are required to validate the safety, efficacy, and dosage of $\mathrm{PH}$-targeted drugs for this rare condition.

Asymptomatic patients with PA usually do not require intervention, especially in the absence of associated cardiac anomalies. However, pulmonary infection or other cardiopulmonary malformations should be treated as early as possible. Asymptomatic patients should still receive regular cardiopulmonary function tests.

In conclusion, $\mathrm{PH}$ is a rare complication of PA requiring early intervention to correct associated malformations and reduce intra-cardiac shunts. Early application of oxygen therapy and medication, including vaccines and PH-targeted drugs, may also preserve cardiopulmonary function by preventing vascular remodeling. Clinicians should recognize that $\mathrm{PH}$ associated with PA increases the risks of morbidity and mortality. Early diagnosis is critical to allow for timely initiation of treatment. Every PA case, even if asymptomatic, should receive regular assessments of cardiopulmonary function starting at an early age.

\section{Contributions}

Yingkang Jin wrote the manuscript, Li Huang made imaging diagnoses, Zhihao Liang conducted molecular genetic testing, Gen Lu was involved in management of cases, and Jiang Wang will act as guarantor for this paper.

\section{Conflict of Interest}

None declared

\section{Source of Funding}

This work was supported by the National Natural Science Foundation of China (grants 81220108001 and 81520108001).

\section{References}

1. Schneider P, Schwabble E. Die morphologic der missbildungen des menschen und der thiere. G Fischer 1906; 10: 812-822.

2. Palma G, Giordano R, Russolillo V, Vosa C. Cardiac defect with diaphragmatic hernia and left lung agenesisheart disease and other anomalies. Thorac Cardiovasc Surg 2010; 58: 439-440.

3. Dobremez E, Fayon M, Vergnes P. Right pulmonary agenesis associated with remaining bronchus stenosis, an equivalent of postpneumonectomy syndrome. Treatment by insertion of tissue expander in the thoracic cavity. Pediatr Surg Int 2005; 21: 121-122.

4. Muensterer O, Abellar R, Otterburn D, Mathew R. Pulmonary agenesis and associated pulmonary hypertension: A case report and review on variability, therapy, and outcome. Eur J Pediatr Surg Rep 2015; 3: 33-39.

5. De Leon-Cantu RE, Rodriguez-Balderrama I, TijerinaCarrillo EL, Villarreal-Castellanos E, Rodriguez-Bonito R, Barbosa-Quintana A, Abrego-Moya V. Right pulmonary hyperplasia with bronchoesophageal fistula. Boletin medico del Hospital Infantil de Mexico 1992; 49: 757-761.

6. Nakayama M, Ito T, Hagiwara H, Asai T, Nakayama T. Ventricular septal defect with right pulmonary agenesis and left bronchial stenosis. Kyobu geka Japan J Thorac Surg 2006; 59: 809-812.

7. Nazir Z, Qazi SH, Ahmed N, Atiq M, Billoo AG. Pulmonary agenesis-vascular airway compression and gastroesophageal reflux influence outcome. J Pediatr Surg 2006; 41: 1165-1169.

8. Guo HW, Pan SW, Song YH, Hu SS. Repair of a ventricular septal defect in a patient with left lung agenesis. J Cardiac Surg 2011; 26: 519-520.

9. Jone PN, Ivy DD. Echocardiography in pediatric pulmonary hypertension. Front Pediatr 2014; 2: 124.

10. Abman SH, Hansmann G, Archer SL, Ivy DD, Adatia I, Chung WK, Hanna BD, Rosenzweig EB, Raj JU, Cornfield D, Stenmark KR, Steinhorn R, Thebaud B, Fineman JR, Kuehne T, Feinstein JA, Friedberg MK, 
Earing M, Barst RJ, Keller RL, Kinsella JP, Mullen M, Deterding R, Kulik T, Mallory G, Humpl T, Wessel DL, American Heart Association Council on Cardiopulmonary CCP, Resuscitation, Council on Clinical C, Council on Cardiovascular Disease in the $\mathrm{Y}$, Council on Cardiovascular R, Intervention, Council on Cardiovascular S, Anesthesia, the American Thoracic S. Pediatric Pulmonary Hypertension: Guidelines From the American Heart Association and American Thoracic Society. Circulation 2015; 132: 2037-2099.

11. Fokstuen S, Schinzel A. Unilateral lobar pulmonary agenesis in sibs. J Med Gene 2000; 37: 557-559.

12. Greenough A, Ahmed T, Broughton S. Unilateral pulmonary agenesis. J Perinat Med 2006; 34: 80-81.

13. Warburton D, El-Hashash A, Carraro G, Tiozzo C, Sala F, Rogers O, De Langhe S, Kemp PJ, Riccardi D, Torday J, Bellusci S, Shi W, Lubkin SR, Jesudason E. Lung organogenesis. Curr Top Develop Biol 2010; 90: 73-158.

14. Verma S, Mahajan JK, Laxmi Narsimha Rao K. Esophageal atresia and tracheoesophageal fistula with unilateral pulmonary agenesis-hypoplasia. J Neonat Surg 2013; 2: 21.

15. Hebert A, Mikkelsen UR, Thilen U, Idorn L, Jensen AS, Nagy E, Hanseus K, Sorensen KE, Sondergaard L. Bosentan improves exercise capacity in adolescents and adults after Fontan operation: the TEMPO (Treatment With Endothelin Receptor Antagonist in Fontan Patients, a Randomized, Placebo-Controlled, Double-Blind Study Measuring Peak Oxygen Consumption) study. Circulation 2014; 130: 2021-2030.

\section{*Correspondence to}

Yiyu Yang

Guangzhou Women and Children's Medical Centre Guangzhou

People's Republic of China 